Trabajos y Comunicaciones, 2da. Época, $\mathrm{N}^{\mathrm{o}}$ 48, e070, julio-diciembre 2018. ISSN 2346-8971 Universidad Nacional de La Plata.

Facultad de Humanidades y Ciencias de la Educación.

Departamento de Historia

\title{
Familias, linajes y poder señorial: aspectos de movilidad y articulación de los entornos rurales a los urbanos en el espacio cantábrico
}

\section{Osvaldo Víctor Pereyra *}

* Universidad Nacional de La Plata - CHAyA (Centro de Historia Argentina y Americana) IdIHCS-CONICET, Argentina

vopereyra@gmail.com

Cita sugerida: Pereyra, O. V. (2018). Familias, linajes y poder señorial: aspectos de movilidad y articulación de los entornos rurales a los urbanos en el espacio cantábrico. Trabajos y Comunicaciones (48), e070. https://doi.org/10.24215/23468971e070

Recibido: 22 de marzo de 2018 I Aceptado: 4 de mayo de 2018 I Publicado: 27 de julio de 2018 


\section{Familias, linajes y poder señorial: aspectos de movilidad y articulación de los entornos rurales a los urbanos en el espacio cantábrico}

Families, lineages and power of the Lord: aspects of mobility and articulation of rural to urban environments in the Cantabrian space.

Osvaldo Victor Pereyra

Universidad Nacional de La Plata - CHAyA (Centro de Historia Argentina y Americana)

IdIHCS-CONICET., Argentina

vopereyra@gmail.com

\section{RESUMEN:}

El siguiente trabajo analiza, en forma comparada, las dinámicas de movilidad socio-territoriales que presentan los linajes menores del área cantábrica asociados a la casa señorial de los Velasco (duques de Frías) en función de la centralidad que presentan las ciudades en el espacio septentrional analizando la dinámica de ascenso y movilización de sus descendientes. Para ello se utiliza el análisis de redes y la comparación de trayectorias y recorridos -colectivos y personales- para componer un cuadro dinámico de interrelaciones y movilidad.

Palabras Clave: Movilidad; Linaje; Ciudades; Dinámica de articulación.

\section{Abstract:}

The following work analyzes, in comparative form, the dynamics of socio-territorial mobility presented by the minor lineages of the Cantabrian area associated with the manor house of the Velasco (Dukes of Frías) according to the centrality of the cities in the northern space analyzing the dynamics of ascent and mobilization of their descendants. To do this, the study of networks and the comparison of trajectories and routes -collective and personal- is used to compose a dynamic picture of interrelationships and mobility.

KEYWORDS: Mobility; Lineage; Cities; Articulation dynamics.

\section{INTRODUCCIÓN}

Los estudios reticulares han mostrado en estas últimas décadas su potencialidad para obtener interesantísimos resultados al investigar las múltiples y complejas interacciones vinculares que vertebraban a las clases dirigentes en las sociedades Antiguo-Regimentales. ${ }^{1}$ Los ARS son una forma abstracta de visualizar interrelación dentro de una serie de sistemas, generalmente complejos (J. J. Merelo Guervós, 1992), basados en la capacidad que poseen sus nodos (actors) de establecer interacciones más o menos densas y dotadas de significado, las cuales determinan aristas (connections) que se encuentran expresadas gráficamente por arcos (bows) y que tienen una direccionalidad (unidirectionality or bidirectionality) que se expresan en términos de grafos de mayor o menor complejidad a cuyo ligado -formulado sobre el conjunto total de la red- definimos como sociograma o matriz. En otras palabras: "se puede decir que el formalismo de redes constituye un metalenguaje para la descripción de la estructura” (P. Hage, 1979: 115).

Simplificando extremadamente el problema, las redes adquieren así un tamaño y una densificación a partir del análisis de las múltiples interacciones compuestas en su interior. En este sentido los niveles de escala espaciales son absolutamente determinantes, tanto para el historiador como para el cientista social abocado en la utilización de estos modelos analíticos-representacionales, para definir la viabilidad heurística en la aplicación de los mismos. ${ }^{2}$ La densificación de información, producto de una definición de escala territorial concentrada, permite al historiador estudiar con mayor detalle los mecanismos de articulación socio-territorial que presentan estos grupos complejos. 
Estos son algunos de los presupuestos de base amplia sobre los que se desarrolla la presente exploración que tiene como objetivo analizar, en un primer momento, el proceso de construcción del entramado de poder señorial llevado adelante por los representantes de la Casa de Velasco en los territorios de Trasmiera y la zona oriental de Cantabria durante los siglos XIV al XV. Formulamos así nuestra primera hipótesis operativa: es el examen del conjunto de intercambios que configuran estas extensas redes señoriales el que nos permite comprender la forma que adquiere la articulación del dominio político territorial, ofreciendo así una imagen dinámica de la construcción del señorío. En un segundo momento analítico, componemos las trayectorias y recorridos que presentan estos agentes señoriales pertenecientes a los linajes menores de la zona oriental y dependientes de la casa de los Velasco. Nuestra segunda hipótesis operativa es la de la participación de aquéllos al interior de la amplia red de administradores señoriales sirve como "trampolín" (springboard) de acceso a otros espacios de la administración, control y gobierno de la monarquía castellana. ${ }^{3}$ Hablamos así de un proceso de movilidad -tanto geográfico como social ascendente- que determina la dinámica de promoción de estos linajes menores, especialmente aquellas ramas colaterales sólidamente asentadas en los ámbitos urbanos.

\section{El linaje como unidad de análisis y la "violencia" como catalizador}

Como sostiene el medievalista cántabro J. A Solórzano Telechea (2004), podemos decir que los linajes se presentan como la estructura básica de organización familiar que dota de coherencia a los grupos más prósperos e influyentes de la sociedad cántabra desde la baja Edad Media. La familia, el linaje, el grupo, su estirpe son espacios de significación que le otorgan existencia y determinan su lugar dentro de un entramado profundamente jerarquizado que dota de sentido a todas las acciones y conductas de los sujetos. ${ }^{4}$ El linaje integraba en su seno tanto a padres, hijos y parientes cercanos, así como también a otros grupos familiares no directos que conformaban sus extensas clientelas unidas, por fuertes lazos de lealtad, a un cabeza de linaje que en el espacio cántabro-vizcaíno recibía la denominación de pariente mayor. ${ }^{5}$ La estabilidad que presentaban estas configuraciones asociativas de poder primarias deviene del hecho de que las mismas reproducían valores de solidaridad y cohesión entre sus miembros, que se encontraban así unidos por un patronímico común que les permitía distinguirse del resto de la población. Dichas estructuras linajísticas se nos aparecen establecidas por un fuerte componente territorial y económico, pues eran el instrumento mediante el cual -los grupos dominantes- garantizaban la apropiación de sus recursos. Estos agrupamientos se hallaban profundamente estratificados e interaccionados a su interior, a partir de relaciones verticales de lealtad y participación que se estructuraban en función de relaciones parentales, de vasallaje o de remuneración monetaria.

Sin embargo, los mismos eran también una configuración asociativa de enorme versatilidad y flexibilidad, pudiendo establecer alianzas más vastas que terminaban conformando los llamados bandos linajes y parcialidades movilizados en función de su dependencia política con los parientes mayores. La violencia banderizada se nos presenta como el "catalizador general" en que se inscribe la articulación socio-espacial de estas estructuras linajísticas.6 Dicha violencia respondía a las propias estrategias de reproducción de estos linajes en los diferentes espacios sociopolíticos: los valles, las juntas, las villas, las parroquias, los señoríos, etc., desarrollando así una violencia tanto horizontal como vertical -por lo que podemos considerarla intraestamental- ya que desciende desde los parientes mayores y linajes principales -a través de sus distintas cadenas clientelares y solidaridad- hasta los sectores más humildes de la población rural y urbana. Ello determina que la finalidad de estas asociaciones inter-linajísticas banderizadas sea exclusivamente una: la defensa del patrimonio de los linajes participantes, así como, el incremento de la influencia social y política de estos en los distintos espacios de señorialización donde se desarrollan. La clara supremacía ejercida por la figura del pariente mayor, al frente de estas alianzas, reproduce el esquema de dependencia y sujeción sobre otros "cabeza de linajes menores", dando por resultado una articulación espacial ampliada centrada en sus clientelas. De esta manera, la lucha de bandos ${ }^{7}$ se proyectaba, no sólo sobre el ámbito rural -donde se 
encontraban sólidamente instalados estos parientes mayores- sino que también abarcaba el interior de los distintos espacios urbanos -donde hallamos sus representantes denominados "parientes menores u ommes buenos de los linajes"- tal como se referencian estos grupos urbanos en la propia documentación. ${ }^{8}$ En la crónica banderiza L. García de Salazar (1492 [1999]) las llamadas Bienandanzas y Fortunas, vemos cómo estos hechos de violencia se continúan y trascienden el ámbito estrictamente local de las villas marítimas y sus entornos rurales movilizando el enfrentamiento de los distintos linajes urbanos y rurales en una espiral de violencia homicida que, si bien presentan las características de venganzas particulares, se encuentran también firmemente relacionadas al proceso general de competencia inter-señorial entre los mismos. ${ }^{9}$

Podemos afirmar que los espacios locales así operaban como "cajas de resonancia" amplificando y potenciando -a través de la violencia intraindividual- el fenómeno de la violencia banderizada. De esta manera es posible entender cómo para los contemporáneos la misma fuera la "causa de los grandes males" que aquejan a las villas en estos territorios. ${ }^{10}$ Los propios informes de los agentes monárquicos hacían eco de la "perturbadora" situación esta espiral de violencia generalizada a la que se encontraban sometidos estos espacios urbanos. En noviembre de 1493, los Reyes Católicos ordenaron al corregidor de las "Quatro Villas de la Costa de la Mar de Castilla" informar sobre las redes de clientelismo generadas al interior de las villas marítimas cantábricas. ${ }^{11}$

La eliminación de los enfrentamientos entre los bandos linajes fue la estrategia política seguida por la monarquía. Para lograrlo era necesario apuntar tanto a la dinámica de captación como también a la forma banderizada de regulación política de estos espacios locales. En el año de 1494, los Reyes Católicos prohibieron las "parcialidades, ligas, confederaciones, apellidos y bandos de las villas" obligando a estas poblaciones urbanas a abandonar: "cualquier liga e confederación e bando al que pertenecieran, bajo pena de perder las propiedades y ser desterrado así como damnificador e enemigo de su patria, e destruidor e quebrantador de la paz, e bien común de ellas... (liberando así a los vecinos de las villas) de la promesas, juramentos y homenajes que tuvieran hechos entre ellos, commo entre cavalleros, escuderos y el pueblo común”. ${ }^{12}$ Cabe destacar que este conjunto de medidas no sólo apuntaron a la desmovilización de los linajes banderizados al interior del recinto urbano, sino que también tienen como blanco a los propios parientes mayores, obligando a los mismos a no "andar acompañados de otras personas que no fueran sus criados propios.” (J. A. Solórzano Telechea, 2004: 194).

En este sentido podemos entender la importancia que adquieren para estos linajes menores las nuevas vías de promoción abiertas por la alianza entre estas oligarquías urbanas y la corona que permitirán solidificar una nueva articulación de poder que dejaba de lado los díscolos parientes mayores obturando las bases mismas de identificación clientelar y afectando decididamente la reproducción de los bandos linajes garantizando para ello, a las oligarquías urbanas, el control del regimiento y sus espacios jurisdiccionales. ${ }^{13}$

\section{De "hidalgos notorios", agentes señoriales y de la monarquía}

Nos centraremos ahora en algunos de estos linajes principales que participan en la red clientelar de dominio político establecida en estos espacios de la actual zona oriental de Cantabria analizando específicamente su dinámica de integración, así como la movilidad territorial y sociopolítica alcanzada. En este sentido me centraré en cinco de estos linajes principales que son: los Arredondo / los Ahedo (Haedo) / los Varado (Alvarado / y los Ibarra (Vega), como ejemplos de estas articulaciones y dinámicas de desarrollo.

Linaje de los Arredondo

Según la documentación proveniente de la casa de Velasco, en los territorios del valle de Ruesga (Trasmiera) el ejercicio de la jurisdicción señorial sobre este valle -juntamente con los de Soba y el de Villaverde- ${ }^{14}$ correspondía a un único corregidor señorial. Este representante era, en tiempos de don Pedro Fernández de Velasco II, Ier Conde de Haro, don Juan García de Redondo (o Arredondo). ${ }^{15}$ Dicho linaje de 
los Arredondo poseía su solar originario en el pueblo de ese nombre ubicado en el valle de Ruesga. ${ }^{16}$ Muchas veces, la antigüedad de este impide saber si es el linaje el que otorga el nombre al lugar o bien es la locación de donde esta familia toma su apellido. Sin embargo, en el caso de los Arredondo hay menciones tempranas de una antigua locación cercana a Santander que -en tiempos de la invasión musulmana- sirvió de refugio vascones, celtas y godos, y así Arredondo pasó a ser el apellido de diferentes familias que pasaron por allí. ${ }^{17}$

Las primeras menciones documentales colocan a los Arredondo participando activamente en las luchas de banderías entre Giles y Negretes ${ }^{18}$ en los territorios de Trasmiera. Lope García de Salazar en sus Bienandanzas e Fortunas, refiere a la importancia de los descendientes de dicho linaje. ${ }^{19}$

Es posible inferir entonces que ese don Juan García de Arredondo -mencionado profusamente en la crónica banderiza- es la misma persona que estuviera al servicio del poderoso linaje de los Velasco. Tenemos datos que concuerdan con ello, por ejemplo, en el reconocimiento de la deuda que mantiene el "concejo" y "hombres buenos de Lorza y Socueva del valle de Ruesga" con los Velasco, correspondiente al pago de "los pechos y derechos" señoriales de estas poblaciones. ${ }^{20}$ De igual forma encontramos menciones a la participación con su parentela en los en los múltiples conflictos en la región e inscriptos en la lucha de bandos, así como en diversos pleitos impulsados contra representantes de este linaje con vecinos de las poblaciones ubicadas en estos espacios de Trasmiera. ${ }^{21}$

Otros documentos hacen referencia a la relación de algunas de las ramas colaterales de este linaje como miembros de la red de agentes señoriales de los Velasco vinculados matrimonialmente entre sí. ${ }^{22}$ Lo cierto es que de este tronco primario de los Arredondo ubicado en Ruesga se irán estableciendo y formando -con el paso del tiempo- distintas casas sobre las ramas colaterales del linaje en Riva, Ogarrio o Bárcena de Cicero ( todas ellas localizadas en la merindad de Trasmiera) y que siempre tomaron como solar principaly originario a los Arredondo de Ruesga. Desde dicho espacio de la "Montaña" representantes de esta familia pasarán posteriormente al Nuevo Mundo repartiéndose así en diferentes lugares de la América española. ${ }^{23}$

La propia difusión heráldica se nos presenta como una prueba más de la centralidad que adquieren estos solares originarios trasmeranos. Los escudos de armas que presentan estas ramas del linaje de los Arredondo varían según los distintos lugares, pero suelen aparecer con elementos claves identificatorios con referencia a la rama principal: "campo de gules, torre de plata, doncella natural, peñas naturales sobre ondas de plata y azur y dos leones de oro. La bordura de azur con veneras de plata”. ${ }^{24}$ Siguiendo el patrón de difusión territorial de esta eráldica en los valles trasmeranos y apoyándonos en la información proveniente de los expedientes de caballería de la Orden de Santiago podemos colegir -como consta en el informe presentado por don Alonso Manuel de Arredondo y Arredondo- ${ }^{25}$ que existían primigeniamente tres casas solariegas antiguas de dicha familia en el lugar de Arredondo, todas ellas entroncadas al mismo solar originario. ${ }^{26}$ Una de esas casonas antiguas de los Arredondo se encontraba junto al río, ubicada "en el puente de Lastra", la misma aparece descripta en el expediente de la Orden de Santiago del coronel de milicias en México, don Fernando Ventura de Arredondo, natural de la localidad de Barruelo. ${ }^{27}$

Otro dato significativo para tener en cuenta es que todas estas ramas de los Arredondo en Ruesga se encuentran asociadas, primigeniamente, al apellido de los Agüero. Éste fue el linaje principal en los valles trasmeranos hasta la llegada de los Velasco, de esta manera es posible inferir que este linaje Arredondo reconocía, en sus comienzos, como "pariente mayor" a los representantes principales del linaje de los Agüero, con los cuales terminaron emparentándose y que, posteriormente, pasaron a formar parte del bando linaje encabezado por los Velasco. Lo que no cabe duda es que estos últimos mantuvieron a los descendientes de los Arredondo en alta estima, reconociéndoles así un lugar preferencial como una de las familias principales en estos valles de Soba, Ruesga y Villaverde. Sus ascendientes aparecen desde temprano asociados, en la documentación de la casa ducal de Frías, a importantes oficios de justicia y administración señorial sobre estos territorios y poblaciones en su conjunto. Podemos decir que en estos espacios señorializados, los Velasco 
sostuvieron el derecho de nombrar por sí mismos los delegados de justicia ${ }^{28}$ optando por la fórmula de un sólo corregidor señorial general representando, en este caso, por los herederos y descendientes del linaje de los Arredondo y auxiliado por un teniente corregidor para cada uno de los valles. En el Archivo de la Nobleza figura también documentación que da cuenta del importante lugar y reconocimiento que seguían ocupando los descendientes de este linaje de los Arredondo en la estructuración del aparato señorial de los Velasco en estos espacios, aún para fechas tan tardías para este seguimiento como los siglos XVII ${ }^{29}$ y XVIII. ${ }^{30}$

De igual forma, la proyección territorial de las distintas ramas del linaje de los Arredondo nos permite visualizar la importancia que tenía para los Velasco la participación de éstos dentro de la estructura de dominio señorial para el control y administración de estos valles. De la antigua casa solar ubicada en la Atalaya -dominante en el valle de Ruesga- desciende la rama colateral de los Arredondo que se instalada en el lugar de Ogarrio, de donde es originario don Diego García de Arredondo Hano, del cual tenemos referencias que datan de finales del siglo XVI, participando como familiar del Santo Oficio de la Inquisición y emparentado con el solar originario a través del matrimonio con doña Leonor de Arredondo y González, natural de Ruesga, e hija de don Juan García de Arredondo, el corregidor señorial, y de doña Catalina González de Ruesga. De esta unión -que fortalece la rama colateral de los Arredondo de Ogarrio- conocemos tres hijos legítimos: Diego $^{31}$, Juan y María de Arredondo y Arredondo, terminando, ésta última emparentada matrimonialmente con la rama de los Arredondo de Riva.

La otra línea del linaje, descendiente del solar originario en la localidad de Arredondo y entroncada con los Agüero, es la representada por don Diego de Arredondo y Agüero casado con su prima, doña Leonor de Arredondo, también natural del valle de Ruesga. ${ }^{32}$ Los descendientes de esta rama son los llamados Arredondo de Barruelo quienes se trasladarán a América -hacia principios del siglo XVIII- tal como describe el expediente de don Fernando Ventura Antonio de Arredondo y Rioseco, ${ }^{33}$ bautizado también en Barruelo en el año de 1726.

Otra línea de la casa ubicada en el lugar de Arredondo, que también enlaza con los Arredondo en Ogarrio, proviene de la figura de don Pedro García de Arredondo, quien contrajo matrimonio con su prima, doña Lorenza de Arredondo. Los descendientes de

esta línea colateral terminó finalmente asentándose también en Ogarrio, teniéndose noticias de dos de sus hijos, don Andrés ${ }^{34}$ y Pedro García de Arredondo y Arredondo. ${ }^{35}$

Finalmente, el solar de los Arredondo de Bárcena de Cicero tiene su origen en la figura de don Pedro de Arredondo, abogado del Consejo Real, natural de Arredondo, quien contrajo matrimonio, en el año de 1581, con doña Catalina de Oceja y Alvarado (hija de don Francia de la Oceja y Sainz del Valle y de doña Catalina Fernández de Alvarado) descendiente del linaje de los Alvarado, ${ }^{36}$ de la antigua familia con solar en Secadura, Merindad de Trasmiera.

Como es posible observar, podemos afirmar que a partir de los reinados de Carlos V y Felipe II, esta baja nobleza o nobleza secundaria entra al servicio real emancipándose, en gran medida, del poder señorial. Un buen ejemplo de ello lo constituye la rama del linaje que conformó la casa de los Arredondo de Riva.

Linaje de los Aedo (Ahedo / Haedo)

En el valle de Villaverde de Trucios ${ }^{37}$ el linaje de los Arredondo se encontraba asociado con otra familia de antiguos "hijosdalgo notables" que eran los Ahedo. Esta antigua familia tiene su primitivo tronco en don García de Aedo, quien acompañó las huestes del rey Don Pelayo ${ }^{38}$. Su solar originario se ubica en el lugar de Ahedo ${ }^{39}$, del valle de Carranza, en el actual partido judicial de Valmaseda en Vizcaya. ${ }^{40}$

Una versión posterior del origen de este linaje -que data de comienzos del siglo XVII- aparece en la obra Topografía e historia general de Argel, ${ }^{41}$ dedicada al obispo de Palermo don Diego de Haedo, que llegaría a ser Presidente y Capitán General del reino de Sicilia nombrado por Felipe II en los últimos años de su reinado, obra escrita por su sobrino, el benedictino Diego de Haedo, abad de Frómista (Palencia), para el día de Navidad de 1605, como una alabanza a su tío, donde resalta su solar y noble cuna, como descendiente de 
un duque de Cantabria y señor de Vizcaya. ${ }^{42}$ Según sabemos, en el valle de Carranza aparecen menciones tempranas de la importancia que adquirían en estos territorios el linaje de los Ahedo / Haedo / Aedo. En las guerras banderizas los vemos participar como parientes menores de este valle y miembros del bando linaje de los Negretes. Frente a ellos se encontraban las familias de San Esteban y los Giles, que eran las cabezas del bando local de los Giles. ${ }^{43}$ Los primeros vivían del río hacia Ahedo ${ }^{44}$ y los otros del río hacia Soscaño. De esta manera, la población caraceña se encontraba dividida entre estas tres familias protagonizando así una serie continua de enfrentamientos durante aproximadamente doscientos años.

Sobre estos espacios territoriales fueron especialmente relevantes los conflictos banderizos entre las Casas de los Salcedo - Salazar (linaje principal de las Encartaciones y oriunda del mismo concejo de Zalla del que proceden originariamente también la familia Aedo) y la Casa de Velasco de Mena (procedente de Carasa, cerca de Laredo, los cuales apoyaron a los Trastámara durante la guerra dinástica, lo que les permitió entonces apropiarse de las propiedades, personas e influencias de su linaje rival de Salazar). Es posible afirmar que las tres primeras ramas familiares de los Ahedo se radicaron tempranamente en los concejos encartados de Carranza, Valmaseda y Zalla.

Siguiendo la información proporcionada por don Lope García de Salazar en sus Bienandanzas e fortunas, estos tres solares primigenios de los Ahedo participaron activamente en el conflicto. Seguramente las casas de los Ahedo de Carranza y de Zalla formaron parte del bando de los oñacinos, que tenía como pariente mayor a los Salazar. Sus grandes enemigos fueron los del bando gamboíno de los Marroquines, que tenían en los Velasco de Mena -la rama colateral del linaje de los Velasco de Frías- como su principal adversario, dominante en la zona de los valles de Balmaseda, Zalla, Villaverde de Trucios y en la villa de Castro Urdiales. La suerte política de estos bandos linajes enfrentados fue variada, pero en líneas generales podemos afirmar que la conclusión del conflicto se dio en forma negativa para el bando linaje comandado por los Salazar y sus aliados, tanto en la zona Vizcaína como en Trasmiera. Las abundantes referencias de los solares de este linaje en las Bienandanzas e fortunas nos permiten obtener una imagen de la importancia que adquiría para los Salazar la alianza política-matrimonial con las familias locales principales para el control de estos territorios, así como también para localizar "espacialmente" la expansión y el fortalecimiento político del linaje de los Ahedo.

La primera expansión se produjo siguiendo el trayecto de la antigua calzada romana que cruzaba la comarca de las Encartaciones desde el valle de Carranza, pasando por la villa de Valmaseda hasta el concejo de Sopuerta - Zalla y continuando por el Norte hacia Laredo - Castro Urdiales y por el Noreste hasta Bilbao. Todas las localidades que estaban situadas junto a la importante vía de comunicación se llenaron en pocos siglos de casas y solares que conservaron el orgullo de las raíces hidalgas y el uso de los símbolos familiares, donde podemos constatar la presencia de la antigua grafía del apellido Aedo.

Con los Ahedo de Valmaseda nos encontramos con el caso de un linaje nobiliario local que, si bien comparte los antepasados y apellido con el solar troncal de Carranza, participan ambas activamente en bandos enemigos durante la larga guerra civil. Es gracias a su alianza con los Velasco cuando esta rama de la familia de los Ahedo logró durante todo el siglo XV, mantener una situación privilegiada tanto en su villa, como en la comarca de las Encartaciones.

Linaje de los Varado (Alvarado)

Varado (Alvarado) ${ }^{45}$ es otro de los linajes de "hidalgos notorios" que, según la leyenda, descienden de unos "caballeros godos de estirpe real", con su casa solar original en Secadura (municipio de Voto), ${ }^{46}$ y que habrían participado como tales a las órdenes del rey Pelayo en la "lucha contra los moros". ${ }^{47}$ Esta versión coincide con la expuesta por Lope García de Salazar. ${ }^{48}$ Siguiendo la crónica banderiza sabemos que la rama troncal del linaje de los Alvarado tiene como "pariente mayor" a los representantes del linaje de los Agüero, con quien terminan entroncándose matrimonialmente a través de uno de los nietos de don Pedro de Secadura, el llamado don Fernando Sánchez del Varado casado con Mari Alonso, hija de Pedro González de Agüero. ${ }^{49}$ 
De esta manera, la posición de este linaje de los Alvarado como "parientes menores" de la poderosa familia trasmerana de los Agüero les permite consolidar su espacio de poder señorial y, al mismo tiempo, motorizar una política matrimonial que determina la alianza de esta familia con importantes linajes locales. ${ }^{50} \mathrm{~A}$ los hijos de este matrimonio los apellidó "del Varado", ya que, a su abuelo, Pedro de Secadura, le habían llamado así con motivo de las dos varas que puso a modo de barandillas en el puente de maderos que construyó sobre el río próximo a su casa. ${ }^{51}$

Según sabemos uno de sus descendientes, el hijo de don Garci Sánchez del Varado (Alvarado), llamado don Sancho García de Alvarado, quien aparece mencionada en las Bienandanzas e fortunas, y en la documentación de la casa de los Velasco, ejercía la prestamería de los lugares de Colindres, Limpias y Liendo y aparece, en el año de 1457, haciendo su "cesión, renuncia y traspaso" a favor de don Pedro Fernández de Velasco, Ier Conde de Haro. ${ }^{52}$ Dicho documento también es acompañado por la "súplica” realizada por don García Sánchez al rey, con la finalidad de que él mismo permita realizar la cesión del oficio a favor del Condestable de Castilla. 53 Su hijo, fue don Fernando Sánchez o Sanz Alvarado, que sigue la línea, señor de la casa de Alvarado de Secadura y Capitán de los ejércitos del Rey de Aragón y del Príncipe Fernando, quien terminó formando parte del aparato de administración señorial de los Velasco y fue nombrado con el oficio de alcalde de los Reales Alcázares de Medina del Pomar, bajo las órdenes del Condestable de Castilla. ${ }^{54}$

Por otro lado, de la rama de los Alvarado en Extremadura ${ }^{55}$ proceden varios descendientes, entre ellos don Juan de Alvarado y Mexía, quien será caballero de la Orden de Santiago, Comendador de las villas de Lobón y Montijo, ambas en Mérida, y como su padre, Capitán General de los ejércitos reales en tiempos de los Reyes Católicos. Su hermano, don Diego de Alvarado y Mexía, que pasa a las Indias en el año de 1499, se asienta en La Española, donde hace fortuna y llegará a ser corregidor. En tanto, el hermano menor, llamado don Gómez de Alvarado y Mexía, fue vecino de Badajoz, Extremadura ${ }^{56}$.

Linaje de los Ibarra (La Vega)

El origen de este linaje de hijosdalgo notorios ${ }^{57}$ se localiza en País Vasco, donde se encuentran los solares originarios en Amorebieta-Etxano ${ }^{58}$ y en Ugarte de Múxika, ${ }^{59}$ donde se constituyen las dos ramas principales que se extienden por todo el territorio de Vizcaya y, por extensión, a los valles de Villaverde y Trucios, donde encontraremos a sus descendientes al servicio del linaje de los Velasco.

Las primeras menciones de la participación de miembros de este antiguo linaje vizcaíno las encontramos en el propio cronista banderizo García de Salazar quien señala el entroncamiento entre el poderoso linaje de los Saldívar (de origen Navarro) y los Ibarra. ${ }^{60}$

Según sabemos por las Bienandanzas e Fortunas, los Ibarra participaban como parientes mayores en el bando de los gamboínos, siendo reputados como uno de los linajes principales. ${ }^{61}$ De esta alianza entre los Saldívar y los Ibarra en los territorios de Durango tenemos noticias de la participación de los mismos en distintos conflictos banderizos relatados por nuestro cronista. Uno de ellos, con fecha de 1468 , nos relata el enfrentamiento entre los Saldívar y los Durango, por la primacía en la villa de Elorrio. Siguiendo a García de Salazar, la contienda entre estos dos poderosos linajes vizcaínos se radicalizó y conllevó al despliegue de fuerzas y la movilización de las lealtades sostenidas por ambos bandos linajes más allá del espacio comarcal en que la misma se desarrollaba. ${ }^{62}$

Es posible resaltar aquí varios elementos, por un lado, la importante participación que tiene en el conflicto el linaje de los Ibarra en su alianza con los Saldívar. ${ }^{63}$ Por otro lado, tenemos que acentuar el hecho de la expansión de la contienda a través de la participación del linaje castellano de los Velasco en la figura del propio "pariente mayor" don Pedro Fernández de Velasco II, el "Buen Conde de Aro", quien envía a sus hijos (don Sancho de Velasco y don Luis de Velasco) a "solicitud" y en apoyo de don Pedro de Avendaño Manrique de Lara ${ }^{64}$-linaje principal del bando de los gamboínos en tierras vizcaínas- aliado de los Saldívar y los Ibarra, contra el bando de los oñacinos, dirigido por los representantes de los linajes de los Múgica (Múxika) ${ }^{65}$ 
y los Butrón ${ }^{66}$-poderosas familias de Vizcaya- tras de la cual se encontraban también encolumnados los Salazar. ${ }^{67}$ La magnitud de las fuerzas movilizadas por estas amplias alianzas linajísticas es también un hecho sobresaliente recalcado por el propio cronista: "E así llegados, ayuntáronse en Ermúa de Durango, fasta IV mil omes muchos armados." ${ }^{68}$ De la dimensión del conflicto y la "matanza" ocurrida en dichos enfrentamientos también hace referencia el propio autor: "E murieron allí juntos X mil omes de Salazar e de Butrón e de Múgica e los otros echaron a huir la cuesta arriba". ${ }^{69}$

La situación cambió sólo dos años después de estos acontecimientos. El lugar de fuerza que terminó ocupando el linaje de los Velasco determinó que el Condestable de Castilla, don Pedro Fernández de Velasco II, fuera designado Corregidor de Vizcaya. Los poderosos linajes vizcaínos sospecharon que la finalidad del Conde de Haro era enseñorear en estos territorios, lo que determinó el reencuentro y la unión entre los linajes de Avendaño, Butrón y Múgica para combatirlo. Los años en que Pedro de Avendaño Manrique de Lara estuvo a la cabeza de la Casa de Urquizu fueron especialmente conflictivos. Esta época se corresponde con una etapa histórica compleja en la que se sucedieron tres monarcas en la Corona de Castilla: Juan II, Enrique IV e Isabel la Católica.

Como podemos observar la expansión del linaje de los Ibarra acompaña el proceso de fortalecimiento de la presencia, en estos territorios, de los Velasco desde su solar originario en Durango. A partir de allí es posible seguir dos líneas de este linaje que terminarán asentándose en los espacios cantábricos. Un primer linaje, que entronca en Vizcaya con los Garaytondo y, un segundo linaje que entronca con los Mendieta. De estos últimos proceden los descendientes de los Ibarra que tomarán como "pariente mayor" al linaje de los Velasco. Ocuparan posiciones importantes dentro de la estructura de gobierno y administración señorial. Por ejemplo, tenemos al bachiller don Nicolás de Ibarra actuando, hacia el año de 1512, como alcalde mayor de don Iñigo Fernández de Velasco en "todas las villas y lugares de la Casa de los Velasco que había heredado tras el fallecimiento de Bernardino Fernández de Velasco." 70 De la misma manera encontramos a éste administrados señorial tomando posesión del valle de Villaverde, como procurador general y en nombre del señor duque de Frías. ${ }^{71}$

Otra rama de los Ibarra se asienta en Marquina de Suso, en la villa de Éibar, son los llamados Ibarra de Yuso y de Suso. Según algunos historiadores el desdoblamiento de esta rama colateral se habría producido hacia mediados del siglo XV. ${ }^{72}$ Podemos decir que de estas líneas devienen aquellos descendientes que pasarán a Nueva España como don Francisco de Ibarra, quien dirigió la expedición contra los amerindios Tepehuanes (al noroeste de México) por orden del virrey Luis de Velasco y Castilla, llamando a estos territorios Nueva Vizcaya. Es allí donde se erige también el actual estado mexicano de Durango, a partir del nombre otorgado por su fundador a la villa americana. Como vemos, dichos nombres remiten a los solares originales del linaje de los Ibarra en tierras altas Vizcaínas.

De este solar de los Ibarra en Éibar también emigran al Nuevo Mundo, en épocas tempranas, Martín de Ibarra y Laurenvide, en septiembre del año de 1526, y Ortuño de Ibarra y Mendilibar, en 1538, llegando a ocupar los importantes cargos en la administración Virreinal de Tesorero General del Reino de Nueva España y factor de su majestad. ${ }^{73}$

\section{Movilidad y dinámica comparada}

En la figura 1 hemos superpuesto -en una apretada síntesis- las distintas trayectorias de estos linajes y sus ramas colaterales. En la parte central del cuadro su disposición en los territorios españoles, a la derecha su proyección a otros destinos en el continente europeo y a su izquierda las distintas posesiones americanas del imperio entre los siglos XVI / XVIII.

Véase figura 1. 


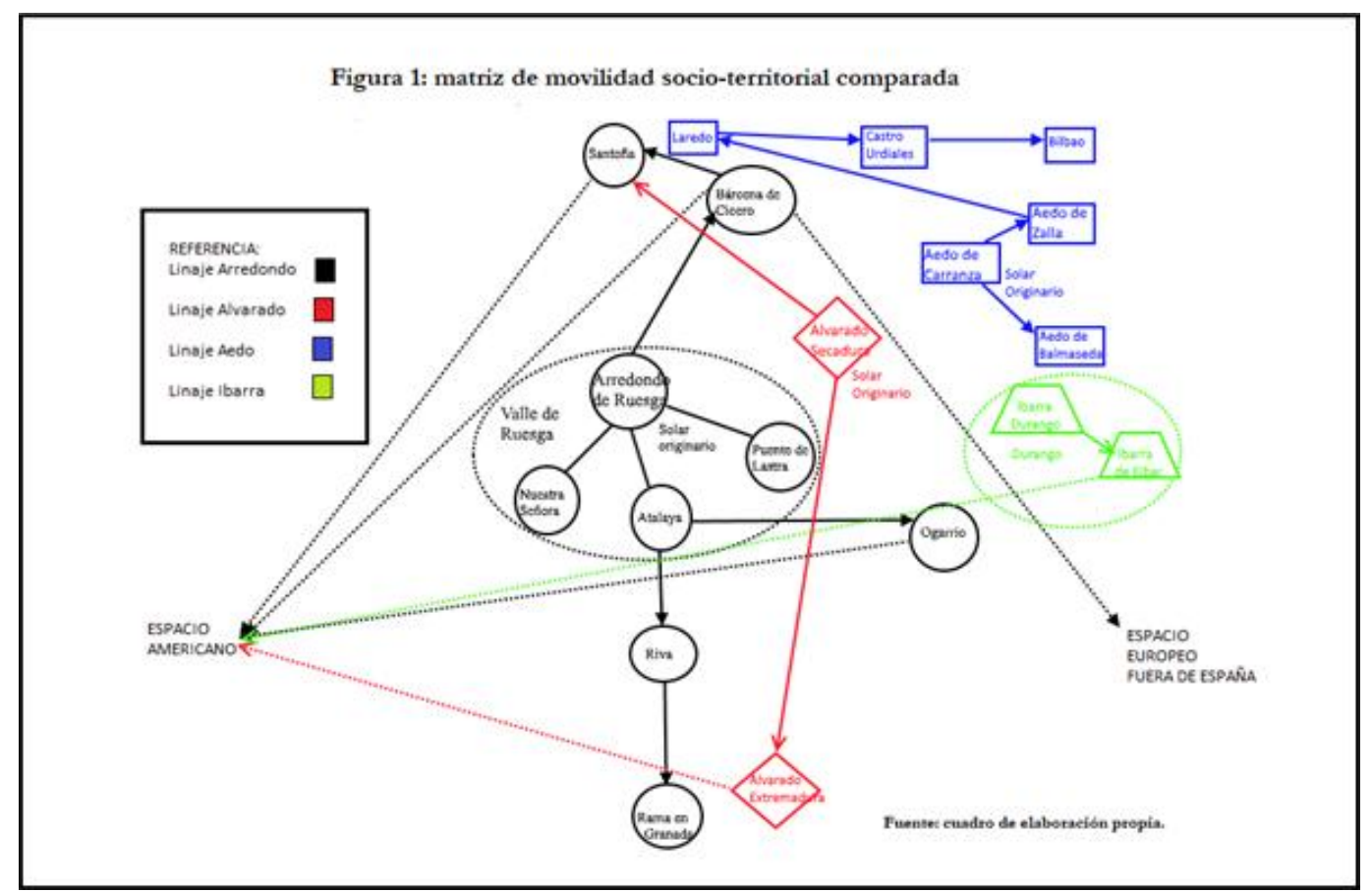

De los linajes analizados, dos de ellos (Arredondo / Alvarado) se desarrollan dentro de una espacialidad que podríamos definir como comarcal / local o de radio corto, mientras que los dos restantes (Ahedo e Ibarra) podemos ubicarlos dentro de un desarrollo regional más amplio o interregional, ya que sus solares originarios se encuentran ubicados en el área de Vizcaya desde donde trasladan sus ramas colaterales al territorio cantábrico. Estaríamos en presencia de una zona amplia de relación y contacto entre estos dos espacios socio-territoriales que -desde la Baja Edad Media- se encontrarían profundamente interrelacionados a partir de estos efectivos humanos articulados en torno a los linajes y sus asociaciones más amplias, los bandos linajes. La participación en la red clientelar de los Velasco no sólo les asegura el fortalecimiento de su poder local sino también la posibilidad de afianzar sus ramas colaterales dentro de una espacialidad más amplia, desde los valles y villas del interior hasta alcanzar las villas marítimas (Arredondo / Alvarado / Aedo) se nos presentan como representantes de este poder expansivo. El caso de los Ibarra se presenta más concentrado -en términos de sus recursos parentales- en el valle de Durango. Como hemos señalado, serán sus ramas colaterales (Amorebieta-Etxano / Ugarte-Múxica) las líneas de los Ibarra que se extienden profusamente en el espacio cantábrico. Las alianzas matrimoniales con los Múxica (Mujica), Saldívar y Avendaño -poderosos parientes mayores del área vizcaína- junto con la unión parental con los Velasco (linaje castellano) afianza el desarrollo expansivo del linaje.

La disposición comparada de estas trayectorias linajísticas nos permite establecer tres momentos claramente delimitados:

1- Momento de establecimiento y consolidación: el cual se encuentra relacionado al solar original. Observamos cómo las ramas colaterales se afianzan en los espacios locales y comarcales a partir de dos tipos de ordenamientos en radios cortos.

A) Pluricéntrico: Linajes como los Arredondo, los Ahedo y los Ibarra presentan una fuerte tendencia a la división primitiva de los solares de origen en los propios espacios donde el mismo se encuentra localizado. Dos o más ramas familiares participan así del despliegue y consolidación de la/s casa/s principal/es. Una explicación que creemos plausible para este fenómeno tiene que ver con la propia dinámica integrativa que poseen los linajes, debiendo por ello asumir que en su origen lo que tenemos es un conjunto de familias cortas que, más allá de la existencia o no de relaciones de parentesco directo o cruzado, reconocen un pariente común del cual hacen derivar su apellido y sus armas. Estamos en presencia de un proceso de identificación, más o menos amplio, no necesariamente centrado en un ancestro en común sino, más bien, en la elección de uno, que se conforma en la imagen mítica del origen. De allí que tempranamente observemos la atomización en diversas ramas que descienden del solar original y que comparten un mismo espacio de expansión. Al mismo tiempo, esta imagen debe ser ponderada en 
función de la preponderancia de una dinámica matrimonial endogámica y cruzada que presentan estos efectivos humanos y que termina, con el tiempo, difuminando las diferencias originarias entre estos grupos primarios.

B) Concéntrico: Un segundo grupo de linajes, como los Alvarado, presentan una morfogenética más concentrada en su origen. Estos grupos se encuentran ya profundamente jerarquizados. El proto-solar vernáculo tiende a reconocer a la familia principal que adopta el apellido, muchas veces del lugar donde se asienta, o bien de características específicas que identifican ese espacio o, simplemente, de las acciones que le valieron su lugar de preponderancia. En este sentido, pueden presentarse múltiples formas o combinaciones de estas.

Sin embargo, cabe destacar que tanto en el modelo policéntrico como el concéntrico (dos vías diferentes para un mismo punto de llegada) una vez consolidado el solar original, éste oficia de tronco común desde donde se desgajan las ramas colaterales, fortaleciendo con ello el proceso de identificación inicial, por lo que sostenemos analíticamente la necesidad de ver a éste como un sólo momento genético de asentamiento y consolidación.

2- Momento de desarrollo y expansión: del mismo hemos hablado anteriormente, simplemente agregaremos que si bien el proceso de expansión se centraliza en torno a la reproducción al interior de estos linajes también es necesario tener en consideración tres factores fundamentales: por un lado, la articulación de los mismos dentro de las asociaciones inter-linajísticas más amplias que son los bandos linajes, por el otro, los diversos entroncamientos matrimoniales con los parientes mayores y, finalmente, su lugar dentro del entramado de agentes señoriales al servicio del poderoso linaje de los Velasco que potencia y asegura su lugar preponderante a nivel local. Es posible destacar aquí la importancia que adquiere, para estos linajes, la consolidación de sus ramas colaterales en los espacios urbanos (tanto en las villas cantábricas del interior como en las villas marítimas o portuarias). Los casos de los linajes de Arredondo / Alvarado y Aedo son claramente ilustrativos al respecto.

Momento de expansión extraterritorial

Finalmente, como podemos observar en nuestra matriz -a través de los ejemplos estudiados- esta expansión extraterritorial descansa, fundamentalmente, en los efectivos de las ramas secundarias fuertemente establecidas en los espacios urbanos a partir de formas de promoción abiertas por la Corona. El fortalecimiento de estas ramas secundarias -que siguen referenciándose al tronco principal- en los entornos urbanos, permite a sus efectivos escalar posiciones al interior del aparato de administración de la monarquía hispana. Dos elementos pues a subrayar dentro de estas dinámicas comparadas de los linajes cántabros: por un lado, la importancia que adquiere la participación de estos linajes locales como agentes señoriales de los Velasco fortaleciendo así las condiciones expansivas de los mismos y, en segundo lugar, la situación privilegiada alcanzada por estas ramas colaterales -parientes menores- en los espacios urbanos que terminarán consolidando su ascenso social como agentes de la corona en espacios lejanos del imperio. La gráfica conjunta de trayectorias nos muestra claramente la importancia que adquiere -para estos sectores- su instalación, desarrollo y lugar preponderante que obtienen en los ámbitos urbanos. Alcanzar los mismos determina la posibilidad de consolidar su poder dentro de los espacios locales y, simultáneamente, proyectar las posibilidades de sus efectivos humanos en los canales de promoción abiertos por la corona. Estos movimientos descriptos son complementarios y se desarrollan en el amplio período que abarca los siglos XV al XVII.

\section{ReFERENCIAS}

Achón Insausti, J. A. (1995) “A voz del concejo". Linaje y corporación urbana en la constitución de la provincia de Guipúzcoa: los Bañez y los Mondragón, siglos XIII al XVI. Diputación Foral de Guipúzcoa.

Álvarez Llopis, E.; Blanco Campos, E., y García de Cortázar, J. A. (1999) Documentación medieval de la Casa de los Velasco referente a Cantabria en el Archivo Nacional, Sección Nobleza. Santander: Fundación Marcelino Botín, 2 tomos. 
Antón Reglero, F. (2004) "El linaje de los Arredondo en la Santoña de los siglos XVIII y XIX" en Monte Buciero, n 10 , pp. 33-55.

Arocena Echeverría, I. (1978) “Los parientes mayores y la guerra de bandos en País Vasco", en Historia del Pueblo Vasco I. San Sebastián: Erein, pp. 151-172.

Blanco Campos, E.; Álvarez LLopis, E. y García de Cortázar, J. Á. (1996) Libro del Concejo (1494-1522) y documentos medievales del Archivo Municipal de Castro Urdiales. Santander: Fundación Marcelino Botín.

Blanco Campos, E.; Álvarez LLopis, E. y García de Cortázar, J. Á. (2005), Documentación referente a Cantabria en al archivo de Simancas. Sección Cámara de Castilla (años 1483-1530). Santander: Fundación Marcelino Botín.

Cadenas López de, A. A. \& Cadenas y Vicent de, V. (1994-5), Blasonario de la consanguinidad Ibérica. Madrid: Hidalguía.

Dacosta Martínez, A. (1999) "De donde se sucedieron unos en otros". La historia y el parentesco vistos por los linajes vizcaínos bajomedievales”, Vasconia, n. 28, pp. 57-70.

Dacosta Martínez, A. (2003) Los linajes en Bizkaia en la Baja Edad Media: poder, parentesco y conflicto. Bilbao: Universidad de País Vasco.

Dedieu, J. P. (2010) "El aparato de gobierno de la monarquía española en el siglo XVIII, elemento constitutivo de un territorio y de una sociedad" en Carzolio, M. I.; Fernández Prieto, R. I. y Lagunas, C. (Compiladoras) El Antiguo Régimen. Una mirada de dos mundos: España y América. Buenos Aires: Prometeo, pp. 39-62.

Díaz de Durana, J. R. (1986) Álava en la Baja Edad Media. Crisis, recuperación y transformaciones socioeconómicas (1250-1525). Vitoria: Diputación Foral de Álava.

Díaz de Durana, J. R. (1998) La lucha de bandos en País Vasco. Guipúzcoa: de los Parientes Mayores a la Provincia (siglos $X I V$ al XVI). Bilbao: Servicio Editorial de la Universidad de País Vasco.

Díaz de Durana, J. R. (2004) La otra nobleza. Escuderos e hidalgos sin nombre y sin historia. Hidalgos e hidalguia universal en el País Vasco al final de la Edad Media (1250-1525). Bilbao, Servicio Editorial de la Universidad del País Vasco.

Díaz de Durana, J. R. y Fernández de Larrea Rojas, J. A., "La frontera de los malhechores: bandidos, linajes y villas entre Álava, Guipúzcoa y Navarra durante la Baja Edad Media," Studia Historica, Historia Medieval, n 23, 2005, pp. 171-205.

Fernández Albadalejo, P. (1975) La crisis del Antiguo Régimen en Guipúzcoa, 1766-1833: cambio económico e historia. Madrid: Akal.

García Carraffa, A. y A. (1920-1963), Diccionario heráldico y genealógico de apellidos españoles. Madrid: Imprenta de Antonio Marzo.

García de Cortazar, J., Á.; Arízaga, B.; Ríos, L. y Del Val, I. (1985) Vizcaya en la Edad Media. Evolución demográfica, económica, social y politica de la comunidad vizcaina medieval. San Sebastián: Haramburu, 4 volúmenes.

García de Salazar, L. (1492 [1999]) Edición de las Bienandanzas y Fortunas de García de Salazar. Edición realizada por Marín Sánchez, A. M. Memorabilia: boletín de literatura Sapiencial, $n^{\circ} 3$, versión electrónica http://parnaseo.uv.es/Lemir/Textos/ bienandanzas

Haedo, Maestro Fray Diego de (1927) Carta dedicatoria al Ilustrísimo y reverendísimo señor Don Diego de Haedo, arzobispo de Palermo, presidente y Capitán General del Reino de Sicilia por el Rey Felipe II, nuestro Señor, en edición de Bauer y Landauer, I. Topografía e historia general de Argel. Madrid: Sociedad de Bibliófilos Españoles.

Hage, P. (1979), "Graph theory as a structural model in cultural anthropology”, Annual Review of Anthropology, vol. 8, pp. 115-136.

Knoke, D. y Yang, S., (2008) Social network analysis. Los Ángeles - Londres: Sage Publications, 2da edition.

Lema, J.; Fernández de Larrea Rojas, J. A.; García E., Munita J., y Diaz de Durana, J. R. (2000) Los señores de la guerra y de la tierra: nuevos textos para el estudio de los Parientes Mayores Guipuzcoanos (1265-1548). San Sebastián: Gipuzkuako Artxibo Orokorra, Archivo General de Guipuzkoa. 
Marín Paredes, J., A. (1998) "Semejante pariente mayor". Parentesco, solar, comunidad y linaje en la institución de un Pariente Mayor en Gipuzkoa. Los señores del solar Oñaz y Loyola (siglos XIV al XVI). San Sebastián: Diputación Foral de Gipuzkoa.

Maza Solano, T. (1972) Relaciones Histórico-Geográficas y Económicas del Partido de Laredo en el Siglo XVIII. Santander: Institución Cultural de Cantabria, Tomo III.

Merelo Guervós, J.J. (1992) “Redes sociales: una introducción”, RedIRIS, Universidad de Granada. Disponible http:// revistaredes.rediris.es/webredes/talleres/redessociales.pdf

Rodríguez Fernández, A. (1986) Alcaldes y Regidores. Administración territorial y gobierno municipal en Cantabria durante la Edad Moderna. Santander: Estudio.

San Martín, J. (1988) "Francisco de Ibarra, conquistador de Nueva Vizcaya y fundador de la ciudad de Durango en México.” Bilbo, n IX-8, pp. 299 a 304.

Solórzano Telechea, J. A. (2004) "Sociedad y violencia de bandos en la Merindad de Trasmiera durante la Baja Edad Media”, en Estudios Trasmeranos, vol. 2, Cantabria, Exmo. Ayuntamiento de Noja.

Valero de Bernabé, L. y Marqués de la Plata, V. M. (1991) Nobiliaria española, Origen, Evolución, Instituciones y Probanzas. Madrid: Prensa y ediciones Iberoamericanas S.A.

Ybarra y Bergé, J. de y Garmendía y Goyetche, P. de (1946) Torres de Vizcaya. Madrid: Instituto Diego de Velásquez de Arte y Arqueología.

\section{Notas}

1 Hablamos de los denominados estudios ARS= Análisis de Redes Sociales o SNA= Social Networks Analysis.

2 "Los escenarios pequeños tienen ventajas considerables al delinear con claridad los límites de membresía y al enumerar las poblaciones de manera exhaustiva... Sin embargo, no hay nada intrínseco en el análisis de redes que impida la aplicación de conceptos y métodos a formaciones de mayor escala, muchas de las cuales poseerán delimitaciones porosas e inciertas." (D. Knoke y S. Yang, 2008: 10).

3 Es importante en este punto resaltar el señalamiento realizado por J. P. Dedieu (2010: 55) hace ya algunos años: "la importancia de la merced, cuyo papel vertebrador vertical ha sigo muchas veces recalcado, pero cuyo papel horizontal de aglutinación de territorios no se suele subrayar con semejante insistencia... mercedes y servicios entre el rey las élites locales son, a nuestro juicio, la base que descansa la conformación territorial del imperio."

4 Debemos tener en cuenta que en Cantabria medieval la organización socio-territorial del espacio se centraba en el solar. En el pasaje al orden feudal una parte de los integrantes de estos solares evolucionaron hacia la configuración de linajes donde, el vínculo agnaticio, marcó decididamente la diferencia sobre el resto de las familias asentadas en el solar. De esta manera, los habitantes de estos solares trasmutaron la jefatura del solar en la jefatura del linaje siendo inseparables, desde ese momento, solar y linaje.

5 En relación con las problemáticas generales de los linajes, bandos y “parientes mayores” en el espacio cántabro-vizcaíno la bibliografía es exuberante: J. A Achón Insausti (1995); I. Arocena Echeverría (1978: 151-172); A. Dacosta Martínez, (2003) (1999: 57-70); J. R. Díaz de Durana, (1986) (1998); P. Fernández Albadalejo (1975); J. Á. García de Cortazar; B. Arízaga; L. Ríos; y I. Del Val, I. (1985); J. A. Marín Paredes, J., A. (1998); entre otros.

6 Tomar la "violencia" como "catalizador general" remite a pensar la misma como un elemento constitutivo en la forma que adoptan las interrelaciones entre estos actores colectivos que son los linajes. Diferentes investigaciones han puesto énfasis -en distintos contextos espaciales y temporales europeos- en la importancia que adquiere la violencia desde el punto de vista configuracional en estas sociedades bajomedievales y temprano modernas. Para dar sólo algunos ejemplos sobre la utilización de la violencia y los "señores de la guerra" en estos espacios septentrionales véase: J. Lema; J. A. Fernández de Larrea Rojas; J. García E., Munita y J. R. Diaz de Durana (2000); J. R. Díaz de Durana (2004) y J. R. Díaz de Durana y J. A. Fernández de Larrea Rojas (2005: 171-205).

7 Los investigadores concuerdan en señalar tres grandes fases en que se desarrolla la "lucha de bandos" en estos territorios: una primera etapa, que se desarrolla entre mediados del siglo XIV a mediados del siglo XV, caracterizada por la violencia y competencia entre bandos. Una segunda etapa, que se extiende desde mediados del siglo XV hasta aproximadamente mediados de la década de los $70^{\prime}$, menos conflictiva que la primera y caracterizada por el acuerdo alcanzado entre los linajes para repartirse pacíficamente el poder. Finalmente, una tercera etapa, que se extiende temporalmente desde 1475 hasta el año 1494, momento en el cual los Reyes Católicos ordenaron la desaparición de los bandos trasmeranos. Dicha resolución fue continuada con la Pragmática Real del 15 de marzo de 1501, en la cual los Reyes Católicos ordenan la 
total disolución de los "bandos linajes y parcialidades", no sólo en Cantabria, sino en los reinos de Galicia, el Principado de Asturias de Oviedo, así como en el Condado de Vizcaya, en la provincia de Guipúzcoa y en las Encartaciones.

8 Biblioteca Municipal de Santander, Sección fondos modernos, Ms. 1479, fol. 5r; 1406, 01, 12. Ejemplo que remite a la villa de Castro Urdiales donde vemos las ramas secundarias de estos linajes rurales poderosos sólidamente instaladas en la villa siendo quienes, una vez implementado el sistema del regimiento, y cuando los monarcas Enrique III y Juan II sancionen el régimen de elección de oficiales a través del reparto de los cargos concejiles por vía de "bando e linaje", terminarán definiendo su propio sistema de regulación política local basado en relaciones parentales que dará como resultado el "cerramiento" del concejo urbano. El cerramiento del concejo urbano resultó ser una fórmula más estable de gobierno con la participación colectiva de los distintos linajes y bandos convirtiendo, al mismo, en un verdadero "señorío colectivo".

9 "Fállase por memoria de los pasados que en el tiempo que reinaba el rey don Pero en Castilla la villa de Castro de Urdiales e muchas ciudades, viendo guerra entre los de ella e de Samano e mucha contienda e omeçidas entre ellos e haciendo su guerra, trajeron los de Castro a Lope Curi de Marquina con muchos omes por su sueldo para hacer guerra a los dichos valles e quemaron una madrugada a Garçi Falda de Ones en la su casa de lastra ensuciada, que es en los Corrales, e a su mujer e fijos e muchos parientes e escapó Garçía de Otañes, su fijo de tres años, que lo sacó una su ama so las faldas, que fue después omne para mucho. Enemistad antigua fue en la villa de Castro entre los Amoroses e Vergones e entre los de la Marca e ovo muertes e omeçidas entre ellos sobre cuál valieran más.” (L. García de Salazar: 981)

10 "1402, noviembre, 11. Sentencia del doctor Gonzalo Moro, oidor de la Audiencia y juez en Castro Urdiales... Sepades que el concejo, e alcalde, et ommes buenos e merino de la dicha villa de Castro de Ordiales dicen... que algunos ommes poderosos que moraban y moran dentro de los dichos términos, que les han tomado et toman et tienen forzado la dicha su jurisdicción del judgado de los dichos términos... dichos escuderos moradores en los dichos términos son poderosos, et paran los más poderosos dellos, alcaldes que consienten los mal fechores e andariegos hacer mal e daño dentro de los dichos términos, et les encubren las sus malfetrias, por lo cual razón dicen que los sus vecinos ni los viandantes non pueden andar seguros por los dichos términos." (Libro del Consejo de Castro Urdiales: doc. 6, 1402) E. Blanco Campos; E. Álvarez Llopis, E. y J. Á. García de Cortázar (1996: 28-33)

11 "En las Cuatro Villas del dicho corregimiento ay linajes y bandos formados de que dicen que son todos los vecinos principales de los pueblos, los que les dicen que eligen cada un año entre sí los oficios de regimiento, sacando cada un linaje por igual los oficios, a fin de fase e gratificarlos cada un año a los de su parte non viendo respeto e idoneidad ni suficiencia a causa de lo cual dicen que las Cuatro Villas no son bien regidas ni gobernadas. E que los dichos regidores e oficiales dicen que llevan cada año de los propios del concejo cierto salario e que en algunas de las dichas villas han crecido el salario, tanto e más que los propios e rentas tienen, e que a esta causa se procuran entre ellos oficios, además de tener poder e facultad para hacer por sus parientes... a causa de los bandos e apellidos que ha habido e ay en esas dichas villas... e de haber parientes mayores que tengan allegados de cuyo bando se llaman los menores de esas dichas villas... dicen que se han recrecido grandes males e muertes seguras, robos, salteamientos, quemas, fuerzas e las personas que los tales crimines e delitos cometen dicen que lo hacen con fuerza de los parientes mayores e de sus casa, donde aunque los encartan e acotan son defendidos e amparados por manera que nuestra justicia non es ejecutada ni ellos como debe, en lo cual dicen que se ha seguido gran deservicio a Dios, nuestro señor, e nuestro, e grande despoblamiento e pobreza de esas dichas villas... que con los dichos bandos e necesidades non poderes entender e entendéis en otros tratos honestos e lícitos ni podíades acrecentar vuestra haciendas” A. G. S. Registro General del Sello, vol. X, fol., 42; 1493, 11, 30.

12 A. G. S. Registro General del Sello, vol. XII, fol. 416; 1494, 11, 07.

13 La articulación de intereses entre las oligarquías y la monarquía generó no sólo la apertura de nuevas vías de promoción para las estrategias de reproducción de estos grupos -ya poderosos a nivel de la villa- sino también la proyección decisiva de su poder sobre el conjunto del territorio. Desde el control de los resortes administrativos y de gobierno del regimiento, estas oligarquías urbanas proyectaron su poder de decisión más allá del propio ámbito urbano, es decir, sobre el conjunto de valles y Juntas que conforman su término.

14 En época moderna este espacio se consolidará en corregimiento señorial englobando los valles de Soba / Ruesga y Villaverde de Trucios, a su frente un corregidor señorial nombrado por la casa de los Velasco, duques de Frías, es uno de los tres corregimientos señoriales consolidados en Cantabria, los otros dos son: “el de la villa de Potes y 'provincia' de Liébana y el que englobaba al 'mayordomado de la villa de la La Vega' y a la de 'honor de Miengo'... en 1567, Juan de Agüero de Santander aparece como corregidor en el valla de Ruesga y en los de Soba y Villaverde 'por el ilustrísimo señor don Iñigo Fernández de Velasco, condestable de Castilla..., señor de los dichos valles.” AHP de Cantabria, Voto. Citado por A. Rodríguez Fernández (1986: 19). De esta conformación es interesante señalar que la circunscripción señorial "desgaja" el valle de Villaverde de las Encartaciones a través de la venta realizada por D. Diego de Avellaneda a favor de D. Pedro Fernández de Velasco, conde de Haro, en el año de 1440 por la suma de 500.000 maravedís. RAH, Colección Salazar y Castro, Signatura: 9/285, fo 181.

15 "Nos el concejo e ommes buenos de Lorca e Socueba que son en el valle que dicen de Ruesga estando ayuntados a nuestra yunta en el lugar que dicen de Ogarruelo, llamados por Iohan García de Redondo, alcalde de la dicha tierra de Ruesga 
por el señor conde don Pedro Fernández de Velasco." (E. Álvarez Llopis; E. Blanco Campos y J. Á. García de Cortázar. 1999: doc. n. 201, T. II, p. 13).

16 Se conserva en la Torre de los Arredondo, en Riba de Ruesga una carta ejecutoria miniada de la familia Arredondo, expedida por Gaspar de Arredondo, vecino de Sevilla y su procurador y fechada en 1571. En ella se dice que: "casa y solar y linaje que llaman de Arredondo, que era en el valle de Ruesga en la Montaña, casa y solar de notorios hijosdalgo y Cabeza de Bando (sic) de las más principales y notorias de sangre noble, conocida así por descendencia de varón como de hembra".

17 Arredondo es denominación vasca, significando arre = piedra / ondo o dondo = cerca o junto, es decir cerca a la piedra o junto a la piedra.

18 Designación general que recibían los bandos linajes en el espacio cantábrico. En el expediente de caballería de don Francisco Gil de Negrete, nacido en Ogarrio el 28 de septiembre de 1584, hijo de don Francisco Gil, natural de Ogarrio, y de doña María de Negrete, nombrado Caballero de la Orden de Santiago en 1650, tenemos una breve descripción de la disposición de los bandos linajes en el valle de Ruesga: "que las familias de Gil y Negrete son dos bandos, no por enemistad, sino por apellidarse unos del bando de los Giles y otro de los Negretes que este valle (de Ruesga) se compone de seis lugares, que tres son del bando de los Giles, los cuales son el lugar de Ogarrio, Valle y Vazuelo, que aunque son dos nombres es un solo lugar, y los otros tres del bando de Negretes, Matienzo, Arredondo y Riva; de todos estos lugares que se compone éste valle, es señor el Condestable de Castilla, el que por composición y medios entre estas familias muchos años ha uso de nombrar alcalde ordinario un año de los de una familia ( Giles ) y otro de los de la otra (Negretes)." Guía Monumental de Ruesga, Localidad de Mentera-Barruelo, http://www.cantabriajoven.com/ruesga/arte/mentera.html

19 "En la tierra de Ruesga ay dos linajes, que uno es antiguo e poderosos en aquella tierra. E de éstos, el que más valió e que ay más memoria fue Gonzalo García de Redondo, que fue omne que valió e ganó mucho. E obo fijos a Juan García e Gonzalo García e Pero García e Ferrán García e Ferrando de Redondo. E de éste e de sus antecesores ay muchos e buenos omes en aquel linaje de Redondo e bien cuantiados." (L. García de Salazar: 858)

20 "Testigos que fueron presentes a lo que he dicho es: Ferrand García de Redondo, e Lope García de Redondo, e... Gonzalo, fijo de Iohan García de Redondo.” (E. Álvarez Llopis; E. Blanco Campos y J. Á. García de Cortázar. 1999: doc. n. 201, T II, p. 16).

21 "Martín de Camino, García de Camino... [otros]... vecinos de Cicero en la Junta de Cesto... Juan de Buega, Juan de la Sierra, García Sánchez de Val de Lastras, Alfonso del Alvarado... [otros]... vecinos del concejo de Secadura... Juan Zapatero... vecino de Rada... otorgan carta poder y procuración ante el escribano Juan Sánchez de Carrias a Juan de Alvarado, alcaide de la fortaleza y villa de Medina del Pomar por el Condestable de Castilla... para que puedan representarles en el pleito que se sigue contra Diego de Redondo y sus hermanos... por la muerte de Diego García... a causa de una saeta y otros golpes recibidos en la reyerta con los citados.” E. Blanco Campos; E. Álvarez Llopis y J. Á. García de Cortazar (2005: 28, año 1487, doc. 11). Del mismo tenor, (2005: 29, año 1487, doc. 12): “Cristóbal Fernández de Sedano, escribano de cámara y de la Chancillería, da fe de la querella presentada en Salamanca con fecha 5 de marzo de 1487, por Juan de Alvarado, alcaide de la fortaleza de Medina de Pomar, ante los alcaldes de casa y corte, contra García de Palacio, alcalde de la puebla de Escalante por don Ladrón de Guevara, por ciertas muertes y heridas ocurridas entre Juan de Alvarado y sus parientes, Diego Sánchez de Redondo, Gonzalo de Redondo, su hijo, Ruy Gutiérrez de la Serna y otros del linaje de los Negretes."

22 "Cristóbal Fernández de Sedaneo, escribano de cámara y de chancillería, da fe de la querella presentada en Salamanca con fecha del 5 de marzo de 1487, por Juan de Alvarado, alcaide de la fortaleza de Medina del Pomar, ante los alcaldes de casa y corte, contra García de Palacio, alcalde de la puebla de Escalante por don Ladrón de Guevara, por ciertas muertes y heridas ocurridas, entre Juan de Alvarado y sus parientes, Diego Sánchez de Redondo, y Gonzalo de Redondo, su hijo, Ruy Gutiérrez de la Serna y otros linajes de los Negretes." Ibid. (2005: 30, año 1487, doc. 12)

23 Tenemos descendientes de la familia de los Arredondo en el "Río de la Plata, Colombia, Costa Rica, Cuba, Chile, Ecuador, Estados Unidos, Guatemala, México, Perú, Puerto Rico, República Dominicana y Uruguay.” F. Antón Reglero (2004: 36).

24 La dama asomada a la ventana, según la leyenda, es una dama de Ausonia encerrada en la torre y guardada por dos leones rampantes. Véase A. A. de Cadenas \& V. de Cadenas (1994-5: 22).

25 Alonso Manuel de Arredondo y Arredondo fue bautizado en Arredondo el 11 de junio de 1641. Fue paje de Alonso Carnero de Zárate, Señor de Chapinería, del Consejo de Italia, con el que pasó a Sicilia como Oficial de Estado y Guerra, y caballero de la Orden de Santiago, en la que ingresó el 29 de octubre de 1686.

26 "Fuimos a la dicha casa que está en medio del lugar, en un alto, lo que demuestra antigüedad y es labrada de cantería con una torre en medio y un balcón que mira al oriente, grande y capaz, con puerta y una tribuna que sale a una capilla conjunta a la dicha casa, la cual es grande y labrada de cantería y crucería con tres altares y en el mayor la imagen de Nuestra Señora de la Concepción en un cuadro y tiene su campana y en la esquina de la capilla mayor un escudo de armas que parece ser un castillo fundado sobre peñas, al cual abrazan dos leones y en las almenas asomada una mujer, y en lo 
alto unas veneras... y las mismas armas tiene la casa que dijeron ser de Joseph de Arredondo, Alcalde de la Corte, que está junto al río." L. Valero de Bernabé y V. M. Marqués de la Plata (1991: 147-150).

27 "En donde se registran dos torres y en medio de ellas una habitación, y en la primera ( torre ) pasado el puente, hay dos ventanas al mediodía y otra al norte y en la esquina que media reconocimos un escudo de piedra de grano embutido en la pared y en él se ve un castillo defendido por una reina con su corona en lo último de la torre, batido por olas de mar y custodiados por dos leones y a sus lados dos manoplas como especie de estrellas y el dicho castillo se adorna con cinco troneras o ventanas y de dos saetías y en su elección con un morrión y dos lanzas atravesadas." Expediente de nobleza de Fernando Ventura de Arredondo, bautizado en Barruelo el 19 de marzo de 1726, coronel de milicias de Guadalajara en Nueva España y Caballero de la Orden de Santiago, en la que ingresó el 2 de septiembre de 1784.

28 "Juan II comunica a los concejos, alcaldes, escuderos, oficiales y hombres buenos de los valles de Soba, Ruesga, Puebla de Arganzón y San Zadornín que, de acuerdo con la información recibida en su consejo, pertenecía a Pedro Fernández de Velasco, su camarero mayor, el señorío de los citados valles con la jurisdicción alta y baja, civil y criminal, con el mero y el mixto imperio y con todas las rentas, pechos y derechos, según los privilegios concedidos por sus antecesores." (E. Álvarez Llopis; E. Blanco Campos y J. Á. García de Cortázar. 1999: doc. 217, T. II, p. 44).

29 “1613, junio, 7. Villaverde. Pleito homenaje de Diego de Arredondo, alcalde de la torre y fortaleza de Villaverde, que tomó Francisco de Quintana, alcalde de Medina de Pomar, en virtud del poder otorgado por Juana de Córdova y Aragón, madre y tutora del condestable Bernardino Fernández de Velasco”. Archivo de la Nobleza de Toledo: Leg. 491/23

30 "1704, septiembre, 10. Valle de Villaverde. Testimonio por Santiago de la Puente, escribano del valle de Villaverde, del reconocimiento que hizo Juan de Arredondo, por orden del condestable José Fernández de Velasco, de los títulos con que los escribanos usaban sus oficios en dicho valle". Archivo de la Nobleza de Toledo: Leg. 491/27

31 Don Diego de Arredondo y Arredondo, llegó a ser caballero de la Orden de Santiago y contador Mayor del Rey en los Reinos de Castilla, emparentándose matrimonialmente con otro de los linajes nobiliarios que participan como funcionarios de la Hacienda Real: los Alvear. Con la figura de su hijo don Gaspar de Arredondo y de Alvear, según su expediente de caballería de la Orden de Santiago, bautizado en Madrid el 23 de diciembre del año de 1613, tenemos el punto de inflexión en el proceso de ennoblecimiento de esta rama secundaria de los Arredondo. Según sabemos este don Gaspar de Arredondo llegó a ser alcalde perpetuo del Fuero de Vizcaya, Veedor General de los Estados de Flandes, así como Contador y Escribano mayor del Reino de Castilla en sus Ayuntamientos juntos en Cortes. La importancia alcanzada por dicho representante de los Arredondo de Ogarrio se verifica también en la alianza matrimonial con el linaje de los Velasco. Su primer matrimonio es con doña María de Velasco Ballesteros, natural de Madrid, y prima del duque de Frías, don Pedro Fernández de Velasco IV. El descendiente legítimo de éste primer matrimonio será el llamado don Pedro de Arredondo y Velasco, vecino de Nestrosa y Caballero de la Orden de Santiago, en la cual ingresó el 23 de diciembre de 1661.

32 De dicho matrimonio desciende don Fernando de Arredondo y Arredondo. Según sabemos por su expediente de caballería de la Orden de Santiago, este representante de los Arredondo dio origen a la rama de los Arredondo en Barruelo.

33 En Barruelo encontramos la casa solar de esta rama colateral de los Arredondo: "situada en el centro del barrio se encuentra la casa de Fernando Ventura Antonio de Arredondo y Rioseco, hijo de Juan Francisco Arredondo Zarauz y de Francisca de Rioseco, nació Fernando en 1726. Fue coronel de milicias de Guadalajara en Nueva España. La casa contaba con portal, caballeriza y dos bodegas, vivienda alta, la que se compone de sala principal con su recibidor, cuatro cuartos que sirven de alcobas, cocina, su sobrado encima de todo esto sirve para echar maíz. Tenía cinco criadas, lo que indica para aquellos tiempos una posición económica muy elevada. Le fue concedida la orden de Caballero de Santiago en 1784. En una esquina de esta antigua casa existe un magnífico escudo... un castillo mojonado y almenado sobre aguas... Armas de Arredondo." Guía Monumental de Ruesga, Localidad de Mentera-Barruelo: http://www.cantabriajoven.co $\mathrm{m} /$ ruesga/arte/mentera.html

34 Según información procedente del expediente de caballería de la Orden de San Juan hecho por su hijo, don José de Arredondo y Arredondo, bautizado en Arredondo el 19 de marzo de 1633, llegó a ser Alcalde de Casa y Corte y Oidor de la Audiencia de la Coruña, Caballero de la Orden de San Juan, Colegial en el mayor de San Idelfonso de Alcalá de Henares y Caballero de la Orden de Santiago, en la cual ingresó en el año de 1679.

35 Escribano del valle de Ruesga, llegó a ocupar el puesto de Procurador General de dicho valle entre los años de 1592 y 1606, su hijo, don Pedro de Arredondo y Arredondo, formó parte también del aparato señorial de administración y de justicia impuesto por los Velasco en estos valles desempeñando el oficio de Teniente Corregidor del valle de Ruesga. Su hijo, don José de Arredondo y Arredondo, fue también alcalde señorial del valle de Ruesga en el año de 1647, y contrae matrimonio con doña Bárbara de Arredondo y Arredondo, natural y bautizada en Riva el 2 de mayo de 1605, representando el entronque de esta rama de los Arredondo de Ogarrio con los de Riva.

36 Según A. y A. García Carraffa (1920-1963: 56). "Noble linaje, que tuvo su primitivo asiento en el lugar de Secadura, de la antigua merindad de Trasmiera, montañas de Santander, y hoy perteneciente al Ayuntamiento de Voto (Junta de Voto), partido judicial de Laredo." 
37 En el Catastro del Marqués de la Ensenada (1750-54) las respuestas de los vecinos aclaran aspectos de la conformación de este espacio: "esta población se llama Valle de Villaverde y que se compone de cuatro cuartos, nombrados el uno el de las Bárcenas, el otro el de Henales, el otro el de la Iseca, y el otro el de Mollinedo... el nombre principal como dejan dicho es el de Valle de Villaverde". A la segunda pregunta respondieron: "Que este valle es de señorío en cuanto a lo jurisdiccional, es el Duque de Frías, quien nombra Corregidor a su elección y Teniente en una persona de las tres que por el valle se le proponen, y a su tiempo toma la residencia correspondiente al Juez que también para ello nombra; y los derechos que se pagan pertenecen a S.M., los cuales se ponen en poder del Procurador Síndico General a fin de que lo ingrese en Arcas Reales en la villa de Laredo y saque las cartas de pago correspondientes”. Fuente: T. Maza Solano (1972: 555-556).

38 Algunos genealogistas sostienen que este linaje procede del caballero García de Aedo, que acompañó en sus luchas a Don Pelayo; mientras otros mantienen que desciende de Don Heduo, duque de Cantabria, que fundó su solar en el valle de Carranza (Vizcaya). Lo que está fuera de toda duda es que el solar más antiguo de este linaje radicó en dicho valle, de donde pasaron a las villas de Valmaseda y Carranza (Vizcaya).

39 Son sus armas: De oro, una encina de sinople sobre ondas de agua de azur y plata, acostado de dos jabalíes de sable empinados a su tronco, uno a cada lado.

40 "El linaje de Aedo de Carrança su fundamento fue en esta manera: que el Señor de Vizcaya dio a una su fija legítima en casamiento con un caballero de Castilla el monasterio de Sant Miguel de Aedo e los maços de Carrança." García de Salazar, L.(1492 [1999]: 847).

41 Maestro Fray Diego de Haedo (1927: 47).

42 "En lo cual muestra bien vuestra señoría ilustrísima su pío y generoso ánimo, y la noble sangre de su nacimiento derivada de aquel ilustrísimo duque de Cantabria, señor de Vizcaya, llamado don Heduo, y de su antiquísima casa solariega de Haedo, sita en el valle de Carranza, que por su honor la llamaban Palacio Heduo. De la cual Alonso Tegui, historiador verídico de los linajes nobles de las Montañas y Vizcaya, en sus versos heroicos dice: También los de Haedo, linaje afamado / Diré cómo vienen de Duques potentes: / De aquel que don Heduo fue llamado. / Amado y querido de todas las gentes. / Tomara de la casa el suelo apellido. / Y corrompió el tiempo cansado. / Porque de Heduo a Haedo ha venido. / Quedando entre todos muy estimado." Ibid.

43 Este secular enfrentamiento entre los Aedo de Carranza y de San Esteban desaparecería a finales del siglo XV, mediante la alianza de las dos familias a través del matrimonio entre sus hijos. Tras el fin definitivo de las guerras banderizas durante el reinado de los Reyes Católicos, se consolidaron cinco grandes mayorazgos o patrimonios nobiliarios que dominaron el valle durante siglos: los Aedo, Santisteban (los San Esteban), Matienzo, Pando y Trevilla.

44 En Carranza aún quedan muestras de las casas torre edificadas durante las guerras de bandos. Una de las primeras que se construyó perteneció al linaje de los Ahedo "Casa Palacio de los Ahedo" en el barrio de Ahedo. Otra de las casas torre que ha subsistido es la de los Llaguno en el barrio del Callejo.

45 Los Señores de la casa de Alvarado del lugar de Secadura traían, ya a principio del siglo XV, las siguientes armas: en campo de oro, cinco flores de lis de azur, puestas en sotuer y en punta ondas de azur y plata.

46 La localidad de Secadura integra el llamado Municipio de Voto -antiguamente valle de Aras- en la Edad Moderna el conjunto de pueblos se engloba en la llamada Junta de Voto, una de las cinco que conformaron la Merindad de Trasmiera y que luego se integrará jurisdiccionalmente el Corregimiento de las Cuatro Villas de la Costa de la Mar de Castilla.

47 Según los hermanos García Garraffa: "noble linaje, que tuvo su primitivo asiento en el lugar de Secadura, de la antigua merindad de Trasmiera, montañas de Santander, y hoy perteneciente al Ayuntamiento de Voto (Junta de Voto), partido judicial de Laredo." A. y A. García Carraffa, (1920-1963: t. I, Apellido: Alvarado).

48 "El linaje d'Elvarado fue su fundamento en Secadura, donde avía un omne mucho bueno que llamaban, Pero Secadura e ganó muchos dineros e grande hacienda." L. García de Salazar, L. (1492 [1999]: 858).

49 "Ferrand Sánchez casó con hija de, Pero González de Agüero y fizo en ella a Juan Sánchez de Alvarado e García Sánchez d'Elvarrado, que valió mucho e pobló en extremeña." Ibid.

50 El primogénito de don Pedro de Secadura, fundador de linaje, llamado también don Pedro de Secadura (el Joven) se casó con la hija de don Martín Velas de Rada, antiguo linaje principal en los lugares de Limpias y Ampuero:"En el valle e logar de Limpias e de Ampuero fueron antiguamente dos linajes e bandos. Pero Velas de Rada es del que ay más memoria que pobló allí e valió mucho e fizo la torre mayor de Limpias. E d'éste sucedieron los fijos de Ferrand Sánchez d'Elvarado, que heredaron aquella torre e solar. E d'éstos pobló allí Sancho García d'Elvarado, que casó con fija de Ferrando Amorós de Salcedo, el de Castro, e ovo d'ella fijo a Sancho García, que pobló allí, que fue mayor de aquel linaje e tiene fijos e fijas e grande parentela." L. García de Salazar, L. (1492 [1999]: 857).

51 Su hijo será don Fernando Sánchez del Varado (Sanz del Varado) que se casó con doña María González de Aguiar, mientras que el segundogénito, don Juan Sánchez del Varado, se casó con la hija de don Ruy Martínez de Solórzano, uno de los representantes de los linajes urbanos más importantes de la villa marítima de Santander. Según sabemos, Juan Sánchez o Sanz de Alvarado, fue el primero que, modificando el Varado. Fue padre de don Juan Sánchez de Alvarado, que sigue la línea, y de don Garci Sánchez de Varado o Alvarado, quien fue señor de la casa de Alvarado en Secadura, 
Corregidor de Córdoba en tiempos de Juan II de Castilla, y uno de los caballeros que acompañaron a Fernán Álvarez de Toledo en la entrada que hizo en la vega de Granada en 1435.

52 "Sepan cuantos esta carta de cesión e traspasamiento e poder vieren como yo, Sánchez García del Varado, vecino de limpias, hijo de Sánchez Garci del Varado, que renuncio e fago cesión e traspasación en vos, don Pero Fernández de Velasco... de la prestamería de los logares de Colindres, e Limpias e Liendo que yo he e tenido e poseo e fasta aquí he tenido e poseído por virtud de un albalá de merced que el rey don Juan, nuestro señor de gloriosa memoria." (E. Álvarez Llopis; E. Blanco Campos y J. Á. García de Cortázar. 1999: doc. 227, T. II, p. 60).

53 "Vuestro humilde servidor... beso vuestro pies e manos e me encomiendo en vuestra alta e real señoría, la cual plugo saber que por el cargos que yo tengo de don Pero Fernández de Velasco, conde de Haro, vuestro camarero mayor, yo querría renunciar e traspasar, e por la presente renuncio e traspaso en el la prestamería de los lugares de Colindres e Limpias e Liendo que yo e poseo fasta aquí de vuestra señoría, por merced e por virtud de un albalá del rey don Juan, vuestro padre, que Santo Paraíso haya." Ibid.., doc. 228, p. 62.

54 Se casó con Beatriz Osorio, con la que fundó y testó Mayorazgo en 1518 ante Pedro Díaz, escribano del lugar de Salazar en Castilla la Vieja. El hijo de este matrimonio fue don Fernando Sánchez o Sanz Alvarado, que ganó fama y nombre en las guerras de Francia, sirviendo al Rey Fernando. Su hijo, Juan Sanz de Alvarado-Bracamonte, quinto Señor de la casa solar y torre-fuerte de Boscariz de Alvarado, sucesor en el señorío, derechos y preeminencias de su padre y abuelos, se casó con doña María de Velasco, hija ilegítima de don Bernardino Fernández de Velasco y de doña Isabel de Velasco, matrimonio que fundamenta la casa de los Velasco y Alvarado que se propaga por América.

55 Solar fundado por el hijo segundogénito de Garci Sánchez de Varado o Alvarado y doña Leonor de Bracamonte, llamado don Juan de Alvarado y Bracamonte, quien llegó a ser comendador de Hornachos (villa del partido judicial de Almendralejo en la provincia de Badajoz) y alcalde de Alburquerque, casado con Catalina de Mexía y Sandoval.

56 Su hijo, Pedro de Alvarado y Contreras, que nació en 1485 en Badajoz, y que luego pasará a América, junto con su tío (el ya mencionado don Diego de Alvarado y Mexía) y del cual sabemos que fue Adelantado de La Florida y Caballero de la orden de Santiago, a la cual se incorpora en el año de 1527, siendo nombrado, años más tarde, Gobernador de Guatemala, después del matrimonio realizado en España con doña Francisca de la Cueva, dama de Ubeda y sobrina del duque de Alburquerque (la cual fallece a poco de llegar a América) y posteriormente con la hermana de la misma, doña Beatriz de la Cueva. Sin embargo, la verdadera compañía femenina de don Pedro de Alvarado y Contreras será, en América, Luisa de Tlaxcala, india noble hija del jefe Tlaxcalteca Xicotenga, quien habría sido entregada por su padre a Hernán Cortés y que fuera ofrecida por éste, en "custodia", a don Pedro. Aunque nunca fuera reconocida como legítima esposa sabemos que tuvo numerosas posesiones y alcanzó el respeto como dama dentro de la sociedad colonial guatemalteca de su época, siendo por ello enterrada en la propia catedral de la capital.

57 Escudo de armas de los Ibarra: Escudo partido: $1^{\circ}$ una banda engolada en cabezas de dragantes, y $2^{\circ}$ cinco hojas de higuera, puestas en sotuer; bordura con ocho aspas.

58 El actual municipio de Amorebieta-Etxano se desarrolla a partir de la antigua Merindad de Zornotza, que comprendía -durante la etapa foral del Señorío de Vizcaya, las Anteiglesias de Etxano, Amorebieta, Ibarruri y Gorozika, así como de la villa de Larrabetzu- donde eran principales los linajes de Ayala, los Salcedo y los Avendaño.

59 Forma parte del actual ayuntamiento de Muxica, junto a la Iglesia de San Vicente, su nombre Urarte o Ugarte significa “entre ríos” siendo allí el linaje principal los Múgica quienes donaron la iglesia a San Millán de la Cogolla.

60 "El linaje de Saldívar fueron allí poblados antiguamente. E el que pobló primero aquel solar de Saldívar fue fijo del Señor de la casa e solar de Ureta, que es Navarra, de los más antiguos d'ella. E de los que d'ellos sucedieron... E d'este linaje d'estos de Saldívar ay muchos buenos parientes, que son de la sangre e linaje d'ellos e son poderosos en aquella tierra." García de Salazar, L. (1492 [1999]: 819).

61 "Pelearon este Juan López de Lezcano e los de Loyola y Aça con Ladrón de Valda e con los de Çaráus e de Iraeta. E murió Martín Pérez d'Enparán, que era uno de los mejores del linaje e bando de Ones. Otrosí murió Martín de Ibarra, que era de los mejores del linaje de Ganboa, e otros doze omes de los mejores de anbos los bandos. E así se partieron, peleando e escaramuzando todo el día, fasta la noche, sin vencimiento alguno." Ibid. 871.

62 "En el año del Señor de mil CDLXVIII años ovo mucha guerra e contienda en tierra de Durango entre los de Çaldívar e de Durango; e no embargante ser enemigos de antigüedad, esto se levantó porque, Pero Roiz de Verris, que vivía cavo Elorrio, que era de los mejores de Durango e mucho natural d'ellos, se fue a la compañía de los de Çaldívar e hubo mucha guerra entre la villa de Llodio e la casa del dicho, Pero Roiz de Ibarra. E dando Juan Alonso de Múxica ayuda a los de Çaldívar e Pero de Avendaño a los de Lorrio, trajo Pero de Avendaño CL omes de caballo del Conde de Salinas con Juan de Verbriesca e de don Sancho de Velasco e don Lois, su hermano, e del Conde de Aro con sus capitanes; e aposentase con ellos Juan de Avendaño, su fijo, en la villa de Lorrio e Pero de Avendaño en la villa de Durango.” Ibid. $902-903$.

63 En el Valle alavés de Llodio, en la villa de Elorrio,se encuentra radicada la llamada Torre de Bitorika Ibarra, uno de los solares más antiguos del linaje de los Ibarra. Véase J. de Ybarra y Bergé, P. de Garmendía y Goyetche, (1946: 246).

64 Pedro de Abendaño y Manrique de Lara, nació en Urquizu hacia 1410. Murió en 1490. Tanto Pedro de Avendaño y Manrique de Lara, como su hijo Juan de Avendaño y Mendoza, estuvieron reiteradamente enfrascados en las luchas de 
bandos acaecidas principalmente en Vizcaya y Álava, sobre todo con sus acérrimos enemigos, los Butrón y los Múgica. Desde que subió al trono de Castilla Enrique IV, fue desterrado en varias ocasiones

65 El apellido vasco Muxika (o castellanizado Múgica) significa helechal. Procede este antiguo linaje del de Abendaño y reconoce por tronco y progenitor a Juan Galíndez de Abendaño, hijo primogénito de Fortún (o Furtado) García de Avendaño, Señor de Aramayona, Múgica y Arteaga. Tocó a Juan Galíndez de Abendaño el Señorío de Múgica o Mújica, villa que hoy pertenece al partido judicial de Gernika, y por ello comenzó a llamarse Múgica, siendo, pues, este linaje de Múgica el que representa la rama principal y directa de los Abendaño. La Casa solar primitiva de este linaje es la Casa-torre en Ugarte de Muxika, cerca de Gernika (Vizcaya), con ramas en Ordizia-Villafranca, Ategorrieta, Oria, Gudugarreta, Goiaz, Idiazabal (en Gipuzkoa), y en otros lugares.

66 La casa-castillo de Butrón se radicó en la anteiglesia de Santa María de Gatika, de la merindad de Uribe, en el partido judicial de Durango, y de aquí sus ramas se establecieron en la villa de Bilbao, Plentzia y en la merindad de Uribe (todo en Vizcaya). Lope García de Salazar arranca su genealogía de Juan Pérez de Axangiz, hijo del segundo Señor de Axangiz (Ajanguiz).

67 "Estando los de la dicha casa de Ibarra en tal afincamiento, vino Juan Alonso de Múxica con todos los parientes de Butrón e de Múxica e todos los escuderos de Arteaga porque Furtud García avía fecho su compañía con él por ser delibrar de su presión. E otrosí fueron a su llamamiento Ochoa de Salazar e Gonzalo de Salazar e Ferrando de Salazar e Juan de Salazar e Pero de Salazar, fijos de Lope García de Salazar, sus primos, e Juan de Salazar Vorte, su hermano, con CCC omes escogidos en todo su solar, a pesar del dicho Lope García, su padre, echándoles su maldición e rogando a Dios que les diese la suya si allá fuesen, él y ellos eran tenidos de ayudar a defender el solar de Butrón e de Múxica por naturaleza e compañía, porque no avían razón ni causa de ir [a] conquistar la tierra e naturaleza de Pero de Avendaño, ca nunca él ni sus antecesores lo avían fecho por qu'él ni a los suyos; e así mesmo fueron contra voluntad de los escuderos del solar, mayores e menores". L. García de Salazar (1492 [1999]: 902).

68 L. García de Salazar (1492 [1999]: 903)

69 Ibidem.

70 (E. Álvarez Llopis; E. Blanco Campos y J. Á. García de Cortázar. 1999: doc. 267, T. II, 143).

71 "Estando ende el señor Nicolás de Ybarra, alcalde mayor del muy excelente señor don Iñigo Fernández de Velasco, condestable de Castilla, duque de Frías, conde de Haro, etcétera... Luego, el dicho señor bachiller Nicolás de Ybarra, alcalde mayor de su señoría, dijo a los sobredichos alcaldes e merino e regidores de dicho valle de Villaverde... el venía a tomar la posesión de todas las ciudades de villas e lugares pertenecientes al dicho mayorazgo e casa de los Velasco." (E. Álvarez Llopis; E. Blanco Campos y J. Á. García de Cortázar. 1999: doc. 268, T. II, 143-147).

72 "La noticia más antigua, de la familia de Ibarra de Eibar, es cuando en 1452 Martín López de Ibarra y su hermana María dividieron a medias el patrimonio familiar dan todos sus montes, heredades, casas molinos, huertas y demás pertenecidos; formando desde entonces las dos casas de Suso y de Yuso. Ambas casas, próximas entre sí, se conservaron en el antiguo arrabal de la villa hasta la última contienda civil, en la que ambas fueron destruidas.” Véase información J. San Martín (1988: 300).

73 Ibidem. 